\title{
Extracción de tofos gotosos. Caso clínico
}

\author{
Extraction of gotous tofos. Clinical case \\ José María del Pino Torres ${ }^{1}$ y Fernando Martínez Merino²

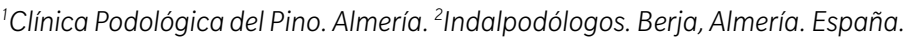

\section{Palabras clave:}

Gota, tumor, lipoma, articulación, hiperuricemia, artritis por microcristales, cirugía podológica, diagnóstico, primera articulación metatarsofalángica.

\section{Keywords:}

Gout, tumor, lipoma, joint, hyperuricemia, arthritis by microcrystals, podiatric surgery, diagnosis, first metatarsophalangeal joint.

\section{Resumen}

El presente artículo muestra un caso clínico de una paciente de 83 años que presentaba dolor persistente a nivel de la primera articulación metatarsofalángica e interfalángicas del pie izquierdo, así como una gran deformidad que le impedía calzarse de forma adecuada. Tras la primera exploración, el diagnóstico de presunción se encaminó hacia la gota. La gota es una enfermedad producida por una acumulación de cristales de urato monosódico en distintas partes del cuerpo como articulaciones, tejidos blandos y riñones. A pesar de que los informes radiológicos apuntaban a otro tipo de lesiones, la clínica indicaba que el diagnóstico clínico estaba más acorde con el problema y se decidió realizar intervención quirúrgica mediante queilectomía de Du Vries para mejorar la sintomatología y eliminar los tofos gotosos del primer dedo y plastia de piel sobrante, con especial cuidado en respetar, en la medida de lo posible, las estructuras plantares para no comprometer la piel plantar y evitar posible fibrosis posterior. Se consiguió alivio del dolor con una movilidad de la primera articulación metatarsofalángica dentro de límites normales, con un primer radio ligeramente insuficiente, pero no siendo necesario un tratamiento postquirúrgico con soportes plantares para mejorar la funcionalidad. Tras más de un año, los resultados obtenidos fueron óptimos, pudiendo hacer una vida completamente normal y con una funcionalidad completamente recuperada.

\begin{abstract}
This article shows a clinical case of an 83-year-old patient with persistent pain at the level of the 1st metatarsophalangeal and interphalangeal joint of the left foot, as well as a large deformity that prevented her from fitting properly. After the first exploration, diagnosis of presumption was directed towards gout. Gout is a disease caused by an accumulation of crystals of monosodium urate in different parts of the body, especially in the joints, soft tissues and kidneys. Although the radiological reports did not comfirm gout, clinical findings indicated that the previous diagnosis of gout was the most probable and a Du Vries cheilectomy was performed to improve Hallux Limitus symptoms and mechanical removal of the first toe gout deposits with an skin plasty to remove excess of skin plasty. Special care was taken to respect plantar structures not compromising the plantar skin in the future and avoid postoperative fibrosis. Pain relief was achieved with a mobility of the first metatarsophalangeal joint within normal limits, with a slightly insufficient first radius, but no postoperative treatment with plantar supports was necessary. After more than a year, the results are optimal, being able to make a completely normal life and with a fully recovered functionality.
\end{abstract}




\section{INTRODUCCIÓN}

La gota se ha conocido desde los primeros tiempos de la historia de la medicina. Rana señaló que Hipócrates describió la gota en el pie como podagra ("podos" que significa pie y "agra" que significa crisis), término que se usó en gran parte de la literatura médica. A menudo, cuando hablamos de la gota, nos vienen a la cabeza sus implicaciones en el pie y tenemos la idea de una enfermedad extremadamente dolorosa. La gota es un tipo de artritis por microcristales que causa dolor y rigidez en las articulaciones y ocurre cuando se acumulan cristales de ácido úrico en estas.

La fase aguda de la gota se caracteriza por el inicio rápido de un dolor, tanto espontáneo como a la palpación, muy intenso, tumefacción y eritema periarticular y aumento de la temperatura tisular, como en la celulitis ${ }^{1}$. La crisis de gota se caracteriza por la precipitación de cristales de urato monosódico en el tejido sinovial, lo que provoca una respuesta inflamatoria aguda. La primera articulación metatarsofalángica se ve afectada en más del $50 \%$ de los pacientes en las crisis iniciales. La cirugía, cuando es necesaria, usa técnicas de artrodesis y desbridamiento articular típicas de la artrosis ${ }^{1}$.

Los niveles de ácido úrico normales son entre 2,4 y 6,0 mg/dl (para las mujeres) y entre 3,4 y 7,0 mg/dl (para los hombres) 2 . Los valores más altos de $100 \mathrm{mg} / \mathrm{dl}$ se deben a un fallo renal que debe ser tratado de forma inmediata porque la urea alta en sangre tiene el potencial de ser mortal ${ }^{2}$.

El presente artículo presenta un caso clínico de paciente con artropatía gotosa. Pese a que el primer diagnóstico iba encaminado hacia gota por el aspecto de las lesiones, las pruebas complementarias apoyaban otros diagnósticos. El tratamiento quirúrgico de las lesiones confirmó la presencia de tofos gotosos confirmando el diagnóstico clínico inicial de gota. Este artículo aporta información sobre los posibles problemas en el diagnóstico de esta enfermedad y discute el valor de las pruebas diagnósticas en el contexto del presente caso clínico.

\section{CASO CLÍNICO}

Mujer de 83 años, sin antecedentes podológicos de interés. Acude a consulta presentando una gran deformidad en el primer dedo del pie izquierdo, tanto en la articulación metatarsofalángica (zona dorsal) como en la interfalángica (plantar medial), de varios años de evolución, pero que ahora le impide calzarse de forma adecuada y llevar una vida normal. Remarcar en este punto que no tenía ningún dolor en la zona ni lo había tenido antes, simplemente se trataba de un problema mecánico (Figura 1).

En tratamiento con Sintrom ${ }^{\circledR}$ comp. 4 mg (Lab. Novartis) (1-0-0), Palexia ${ }^{\circledR}$ comp. recub. con película 50 mg (Grünenthal Pharma) (1-1-1), Actiq ${ }^{\circledR}$ comp. 200 mcg (Grünenthal Pharma) (1-1-0), Zopiclona ${ }^{\circledR}$ comp. recub. con película 7,5 mg (Qualigen) (1-0-0), Ramipril ${ }^{\circledR}$ comp. 10 mg (Cinfa)

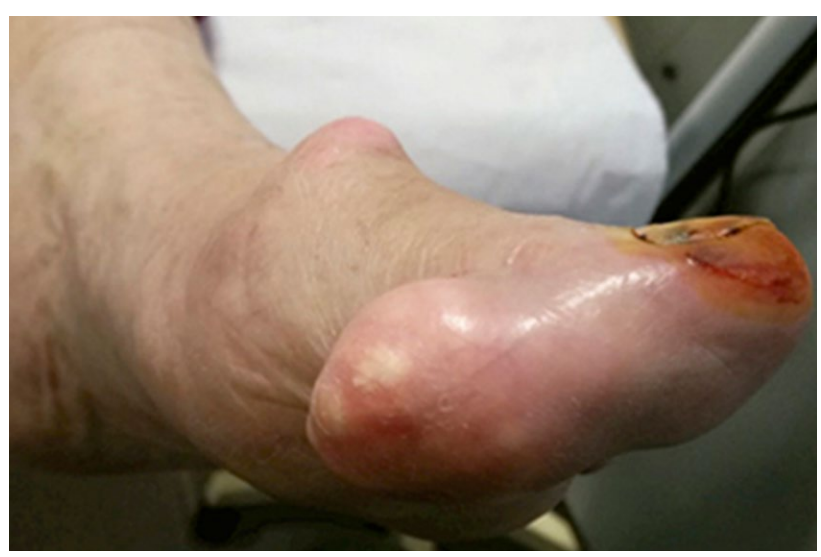

Figura 1. Aspecto preoperatorio de la lesión, aún por determinar.

(0-1-0), Cromatonbic ${ }^{\circledR}$ B12 (Laboratorios Menarini [Menarini Grupo]) (0-0-1), Omeprazol EFG cáps. dura gastrorresistente $20 \mathrm{mg}$ (Aristo) (0-1-0).

Presenta evidentes problemas circulatorios asociados a su edad, no siendo posible identificar los pulsos mediante la palpación directa. En el examen ecográfico podemos identificar correctamente el flujo en la arteria pedia, no así la arteria tibial posterior, la cual presenta una leve obliteración.

El ITB (índice tobillo-brazo) era de 0,8, mientras que el de antepié-brazo es de 0,7 , identificándose con sonda doppler 2 de las 4 arterias digitales.

Ante esta lesión, se pidieron pruebas complementarias, tanto radiografías como, analítica, RMN y TAC, que arrojaron los siguientes resultados:

- Las pruebas analíticas de hemograma y bioquímica de la paciente mostraron rangos de valores dentro de la normalidad para el tipo de paciente y su edad, siendo especialmente sorprendente los niveles de urea en la bioquímica de $2,6 \mathrm{mg} / \mathrm{dl}$, teniendo como referencia un rango 2,4 y 6,0 mg/dl para las mujeres.

- La exploración ecográfica del primer radiólogo nos habla de "cambios en la zona metatarsofalángica del primer dedo. Formación nodular de tejidos blandos en la cara interna del primer dedo, a considerar lipoma, fibroma, dermofibroma, menos probable tofo gotoso" (Figura 2).

Dada la imposibilidad de establecer un diagnóstico certero con esta prueba, y que en un primer momento nuestro diagnóstico iba encaminado al tofo gotoso, se decide solicitar una segunda exploración, en este caso una RMN, cuyo informe dice textualmente: "Lesión nodular de $26 \mathrm{~mm}$ aproximadamente, localizada en cara plantar de la falange del primer dedo, con intensidad de señal baja en todas las secuencias; aparece bien delimitada, contactando con el tendón del flexor del primer dedo, con el que pierde el plano grado de separación". Las conclusiones del informe/estudio son: "Lesión sólida en el tejido celular subcutáneo del primer dedo, sin signos de agresividad 


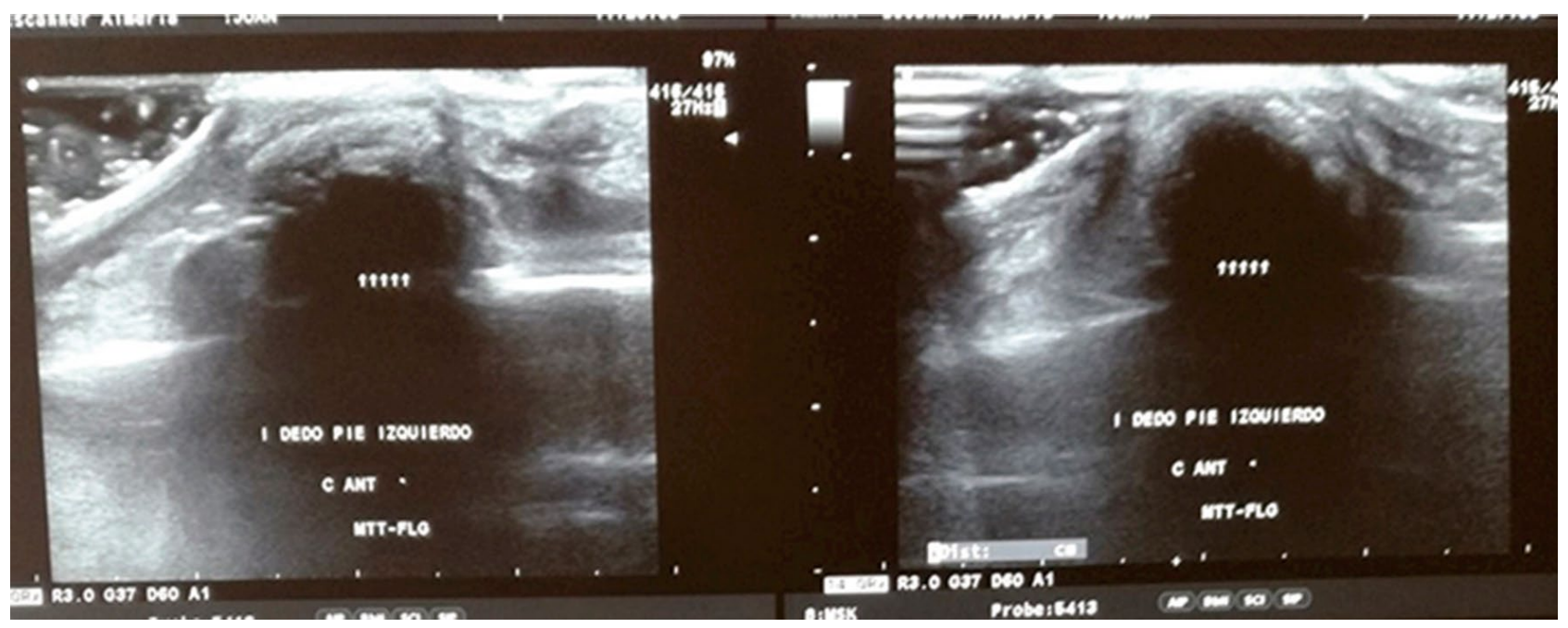

Figura 2. Ecografias previas al tratamiento.
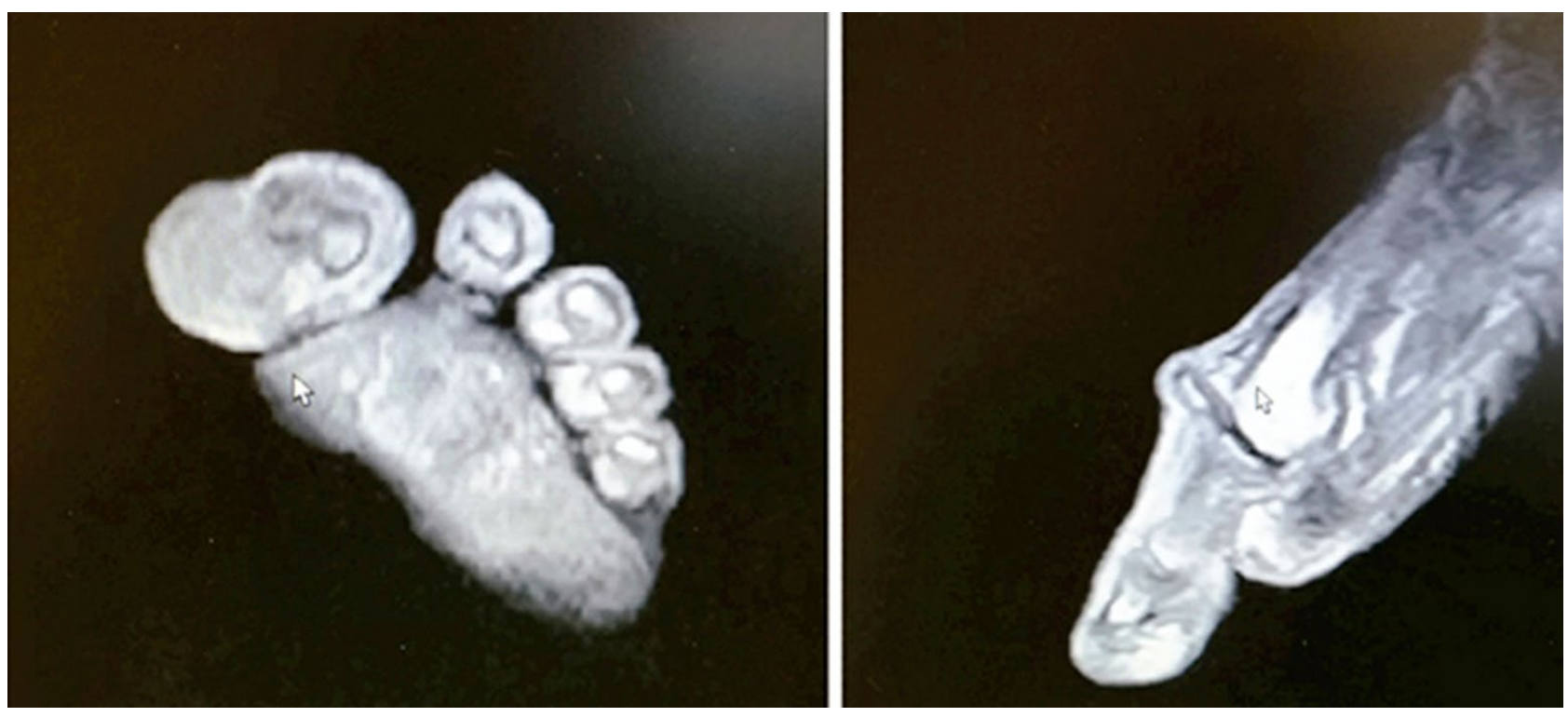

Figura 3. RMN en la que se aprecian tamaño y localización de las lesiones, además de la afectación de la 1a MTF izquierda.

local. Posible tumor de células gigantes de la vaina tendinosa. Hallux rígidus" (Figura 3).

Nos encontramos ante la imposibilidad de establecer un diagnóstico certero con las pruebas realizadas, con dos informes de dos radiólogos diferentes y con dos diagnósticos diferentes entre sí, a lo que en un principio pensábamos como presunción diagnóstica, es decir un tofo gotoso. Más aún si tenemos en cuenta las pequeñas lesiones aisladas que se presentaban el AIF del $2^{\circ}$ dedo del mismo pie, lo cual nos reforzaba en nuestra suposición inicial de que se trataba de un caso de gota.

En cualquier caso, el tratamiento indicado era la cirugía para eliminar la lesión y corregir la deformidad, devolviéndo- le al dedo su funcionalidad perdida y a la paciente su calidad de vida.

\section{Procedimiento}

Por todo ello, se decidió emplear un proceso de toilette articular para extraer la lesión, combinándolo con una queilectomía de Du Vries para eliminar el hallux límitus ${ }^{3}$, el cual se realiza el 23 de noviembre de 2017 en el quirófano de Policlínica de Roquetas de Mar (Almería).

Se intervino a la paciente bajo anestesia local (mepivacaína $2 \%, 10 \mathrm{cc}$ ) con bloqueo de Mayo para el primer radio, sin 


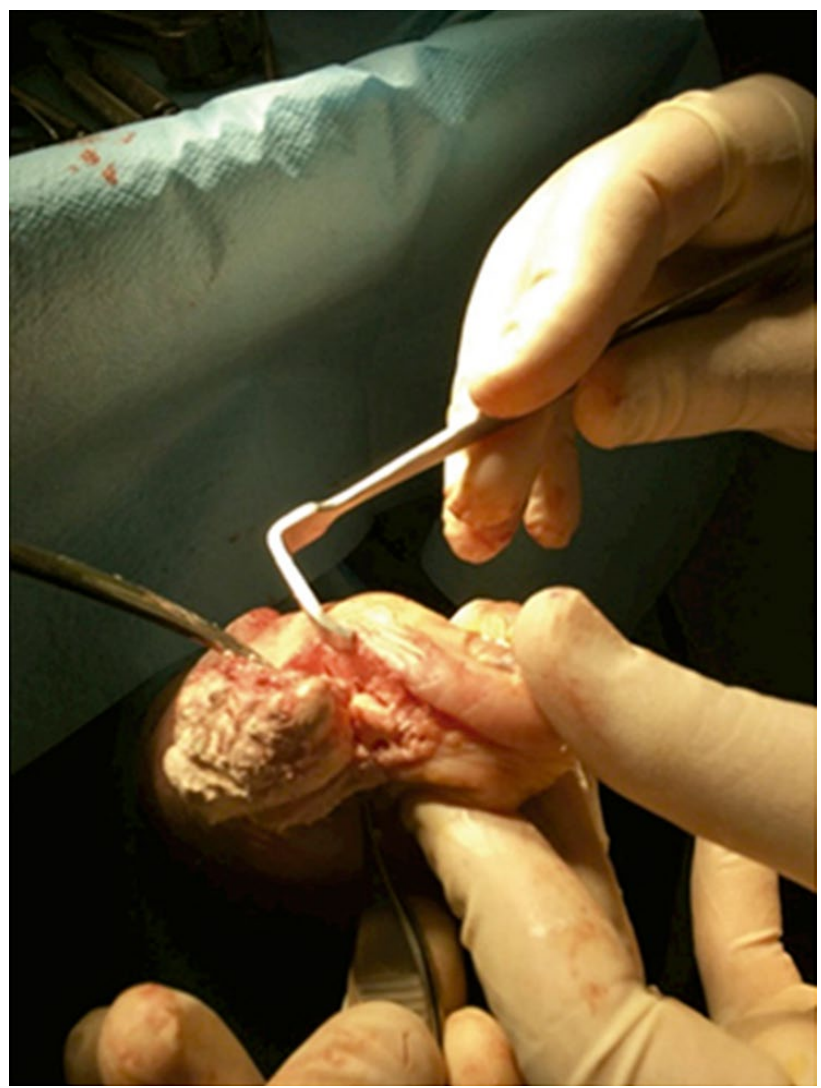

Figura 4.

sedación y con la paciente monitorizada y con una vía permeable en todo momento. La paciente estuvo consciente, orientada y habladora durante todo el proceso, el cual duró 1 hora y 30 minutos.

Se realizó isquemia de tobillo, por lo que para reperfundir los tejidos distales y evitar un compromiso vascular posterior, los últimos 20 o 30 minutos aproximadamente se trabajó sin isquemia, dada la avanzada edad de la paciente y sus problemas vasculares declarados.

La queilectomía de Du Vries es un remodelado de la corona osteofítica articular dorsal del metatarsiano y de la falange para mejorar el dolor y la flexión dorsal; estaría indicada en los estadios II y III ${ }^{4}$. A través de una incisión longitudinal dorsolateral o dorsal a nivel de la primera articulación metatarsofalángica, se realizó una liberación de la cápsula articular que se rechazó lateralmente junto con el tendón extensor del Hallux. Realizamos una capsulotomía y se extirparon los cuerpos libres, resecando los osteofitos y un $25 \%$ de la porción dorsal de la cabeza metatarsal mediante un corte oblicuo que también se puede asociar la resección de una pequeña cuña de la base de la falange (Figura 4), con la finalidad de aumentar la dorsiflexión ${ }^{4}$. Se revisaron las posibles adherencias entre los sesamoideos y la cabeza metatarsal en su cara plantar. Se debía lograr una dorsiflexión aproximada de $60^{\circ}$, ya que en el postoperatorio siempre tiende a reducirse ${ }^{5,6}$.

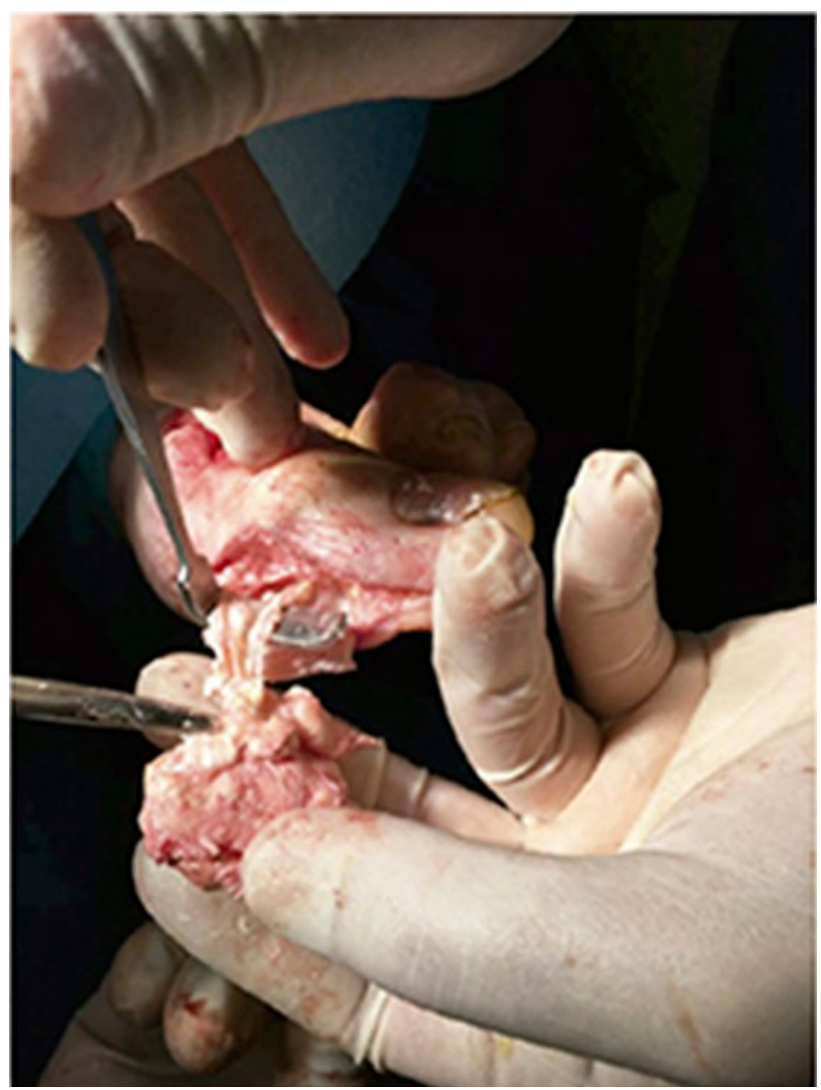

Figura 5.

Se realizó una incisión dorsal a la AMTF para corregir el hallux rígidus y eliminar el tofo gotoso dorsal, y otra en lateral hasta distal-plantar en el dedo, para poder abarcar toda la lesión de la AIF que, recordemos, es el motivo principal de la intervención.

Se extrajo la lesión con mucho cuidado, puesto que a pesar de su consistencia sólida, se desprendían numerosos fragmentos que fueron retirados uno a uno de la zona para un cierre correcto (Figura 5).

Se puede observar cómo el paquete vasculonervioso se encontraba completamente adherido a la lesión, esta lo rodeaba por completo y se hacía imposible extirpar el tofo sin eliminar parte del paquete vasculonervioso medial (Figura 6). Para ello, se realizó una correcta neurotomía, por el riesgo de provocar un neuroma de muñón posteriormente 7,8 .

Una vez extraidos todos los fragmentos y bien limpia la zona, se procedió a cerrar, con sutura continua, no reabsorbible, la cual se mantuvo por 4 semanas, durante las cuales la paciente llevó permanentemente una bota Walker corta para evitar el apoyo de la zona en la medida de lo posible.

A consecuencia del tamaño de las lesiones extirpadas y de la edad y condiciones de la paciente, nuestro mayor temor es que hubiera una esclerosis/fibrosis de la zona plantar por el poco tejido graso que quedaba bajo la falange distal, y ello 


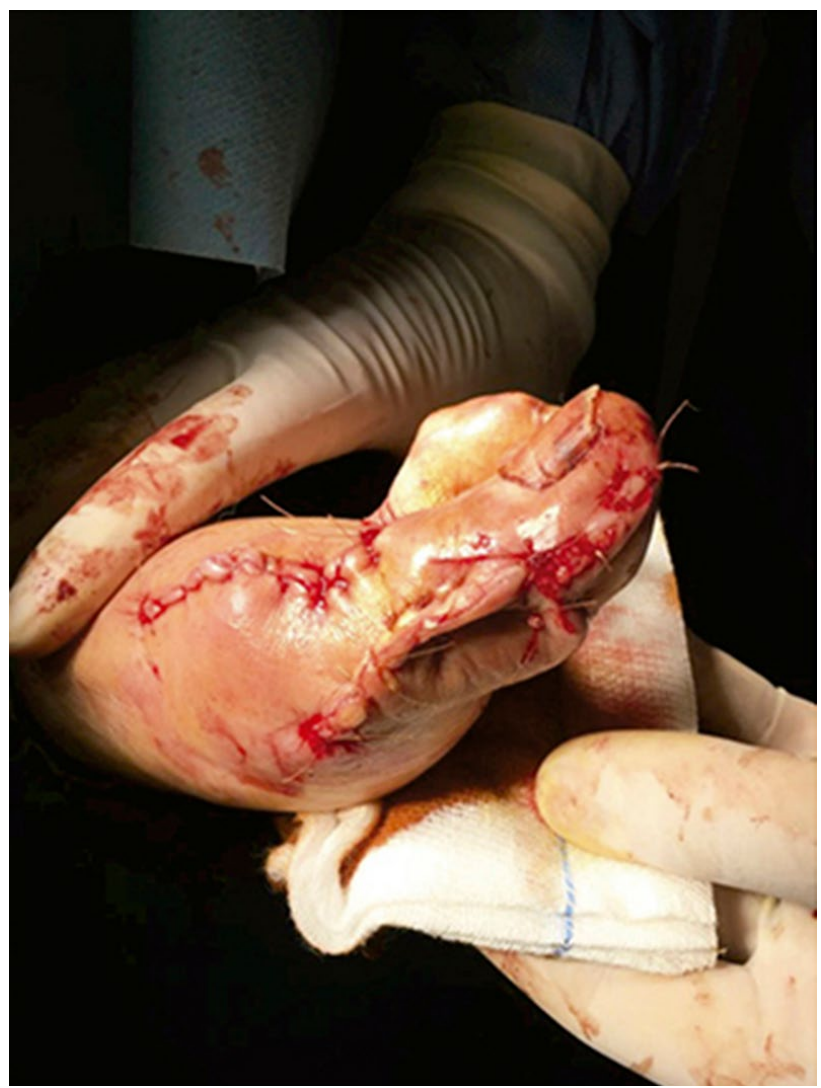

Figura 6. Detalle de la sutura empleada, continua y no absorbible.

degenerase en una ulceración con todos los problemas que puede acarrear dicho proceso. De ahí la importancia de mantener un postoperatorio correcto y evitar el apoyo de la zona en la medida de lo posible ${ }^{8}$.

La paciente no sufrió molestia alguna durante el proceso postoperatorio inmediato, para lo que usamos una combinación de tramadol y paracetamol, Zytram Byd $75 \mathrm{mg}$ comp. de liberación prolongada (Mundipharma) (1-1-1) para reducir el dolor postoperatorio. Además, se le infiltró en el mismo quirófano al terminar la cirugía un vial de dexametasona fosfato $4 \mathrm{mg}$ (Fortecortín $1 \mathrm{ml}$, Lab. ERN) de forma intralesional, lo cual ayudó en gran medida a evitar el dolor postoperatorio inmediato y la inflamación excesiva, aportando a la paciente un grado extra de confort.

Se realizaron curas semanales durante las 6 semanas posteriores a la intervención, de forma satisfactoria y sin episodios reseñables, tras lo cual se procedió a dar el alta provisional, lo que conlleva que la paciente siguió en seguimiento durante los meses posteriores a la intervención (Figura 7).

Tras las pertinentes curas postoperatorias, y aproximadamente a los 2 meses de haber realizado la cirugía, procedimos al dar el alta provisional a la paciente, la cual siguió acudiendo a revisión por un periodo no inferior a 6 meses, para poder evaluar de forma exhaustiva su evolución y así

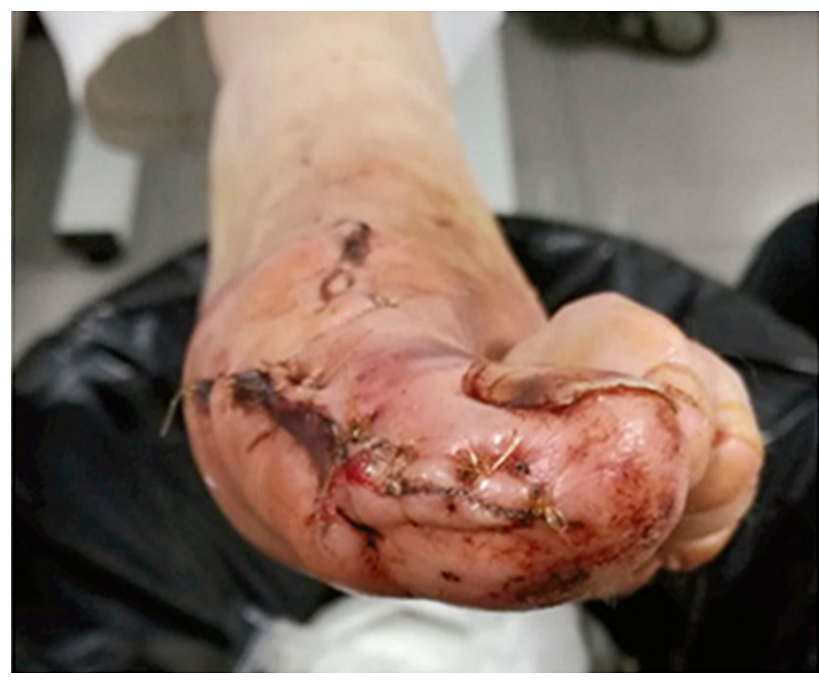

Figura 7. Detalle de la primera cura. No hay apenas inflamación local, y una leve equimosis propia en este tipo de procesos.

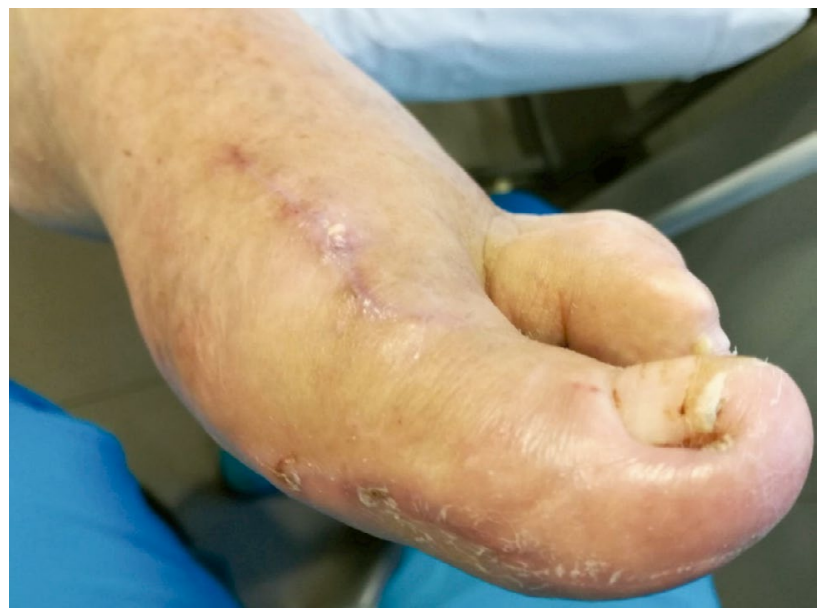

Figura 8. Aspecto final del proceso al día del alta. La zona está completamente recuperada y sin ninguna molestia.

prevenir posibles complicaciones derivadas del proceso. En el momento de redactar el presente artículo ya usa calzado normal y es plenamente autónoma, no habiendo notado en ningún momento del proceso de curación molestia alguna ni signos de inflamación o infección postoperatorias, por lo cual es una cirugía con un alto grado de satisfacción tanto para la paciente como para el equipo quirúrgico que participó de la misma (Figura 8).

\section{Informe de Anatomía Patológica}

El informe del laboratorio de Anatomía Patológica vino a confirmar nuestras sospechas iniciales de que se trataban de tofos gotosos, pese a los dos informes contrarios de dos radió- 
logos diferentes y a las pruebas de laboratorio, arrojando los siguientes resultados:

- Informe de resultados:

- Informe de Anatomía Patológica:

I Descripción macroscópica: fragmento óseo de $2 \mathrm{~cm}$.

I Diagnóstico: fragmento óseo con tofo gotoso.

- Informe de Anatomía Patológica:

I Descripción macroscópica: fragmento nodular de 3,5cm. Inclusión parcial.

I Diagnóstico: tofo gotoso.

Timeline

Ver Tabla I. Tras evaluar a la paciente a los 6 meses y al año de la intervención, podemos afirmar que la operación y su posterior recuperación han sido exitosas, no habiéndose presentado ninguna incidencia de relevancia en el proceso de recuperación, y con un dedo y una primera articulación metatarsofalángicas completamente funcionales y una total ausencia de dolor.

\section{DISCUSIÓN}

El presente artículo presenta un caso clínico de paciente con artropatía gotosa. Pese a que el primer diagnóstico iba encaminado hacia gota por el aspecto de las lesiones, deci- dimos apoyarlo con pruebas complementarias, tanto de laboratorio como de imagen, para lo cual solicitamos análisis de sangre para conocer los niveles de uricemia, además de ecografía y resonancia magnética para valorar la lesión. Los niveles de uricemia se encontraban dentro de los márgenes de normalidad para la edad de la paciente. A esto, además, habría que unir que la paciente no tenía ningún tipo de molestia que se pudiera relacionar con la gota clásica, su problema era puramente mecánico ya que no se podía calzar. Igualmente, las pruebas de imagen, lejos de aclarar el panorama, nos indicaban un camino completamente opuesto, señalando otro tipo de lesiones de carácter tumoral. La clínica que presentaba la paciente no era completamente acorde a los signos y síntomas clásicos de gota que se describen al principio. No presentaba dolor a la palpación y/o movilización, no había eritema ni tumefacción periarticular ni ningún otro signo que nos pudiera identificar las lesiones como depósitos de urato monosódico, más allá del aspecto de las lesiones en sí, muy característico de esta enfermedad. Por ello, decidimos que la única solución sería tratar de forma quirúrgica para, por un lado, devolver la funcionalidad a la primera articulación metatarsofalángica y, por el otro, eliminar las lesiones mediales y plantar del primer dedo y permitir a nuestra paciente que pudiera hacer una vida normal.

Las conclusiones que podemos extraer del presente caso clínico son claras. La gota es una enfermedad bastante frecuente y que tiene una clara repercusión en el pie, la cual hemos de conocer, diagnosticar y tratar de la forma más adecuada a cada paciente. En el presente caso, el tratamiento

\begin{tabular}{|c|c|c|c|}
\hline Fecha & Acto & Datos de relevancia & Observaciones \\
\hline 15-09-2017 & 1. ${ }^{\mathrm{a}}$ consulta & Dolor en primer dedo pie izquierdo & Diagnóstico presunción: tofo gotoso \\
\hline 29-09-2017 & 2. ${ }^{\text {a }}$ consulta & Aporta pruebas complementarias & Analítica, valores normales \\
\hline $10-10-2017$ & 3. ${ }^{\mathrm{a}}$ consulta & Aporta pruebas complementarias & Ecografía: lipoma \\
\hline 13-10-2017 & 4. ${ }^{\mathrm{a}}$ consulta & Aporta pruebas complementarias & RMN: tumor células gigantes \\
\hline 07-11-2017 & 5. ${ }^{\mathrm{a}}$ consulta & Planteamiento quirúrgico & Informe preoperatorio MAP \\
\hline 10-11-2017 & 6. ${ }^{\mathrm{a}}$ consulta & Consulta preoperatoria & Encuesta de autochequeo \\
\hline 23-11-2017 & 7. ${ }^{\mathrm{a}}$ consulta & Intervención quirúrgica & Extracción de dos lesiones \\
\hline $27-11-2017$ & 8. ${ }^{\mathrm{a}}$ consulta & 1. ${ }^{\mathrm{a}}$ cura & Correcta evolución \\
\hline $01-12-2017$ & 9. ${ }^{\text {a consulta }}$ & 2. ${ }^{\mathrm{a}}$ cura & Correcta evolución \\
\hline 07-12-2017 & 10. ${ }^{\text {a }}$ consulta & 3. ${ }^{\mathrm{a}}$ cura & Correcta evolución \\
\hline $14-12-2017$ & $11 .^{\mathrm{a}}$ consulta & 4. ${ }^{\mathrm{a}}$ cura & Correcta evolución \\
\hline $21-12-2017$ & 12. ${ }^{\mathrm{a}}$ consulta & 5. ${ }^{\mathrm{a}}$ cura & Correcta evolución \\
\hline 29-12-2017 & 13. ${ }^{\mathrm{a}}$ consulta & 6. ${ }^{\mathrm{a}}$ cura & Correcta evolución. Alta provisional \\
\hline 30-01-2018 & 14. ${ }^{\mathrm{a}}$ consulta & Revisión tras alta provisional & $\begin{array}{l}\text { Informe Anat. Patológica confirma tofos gotosos. Alta } \\
\text { definitiva }\end{array}$ \\
\hline 29-06-2018 & Revisión & Revisión semestral & Sin incidencias. Evolución correcta \\
\hline 30-11-2018 & Revisión & Revisión anual & Sin incidencias. Evolución correcta. \\
\hline
\end{tabular}


era eminentemente quirúrgico por el tamaño, localización y molestias que provocaban las lesiones a una paciente que no se podía calzar de forma correcta.

Pese a que todas las pruebas previas apuntaban en otra dirección, nuestra experiencia clínica nos llevó al diagnóstico correcto desde el primer momento y, como tal, planificamos el realizar una técnica de queilectomía de Du Vries, más indicada en este caso para preservar mayor cantidad de cartílago articular, y obtener así una articulación lo más funcional posible, que es, a la postre, lo que buscábamos desde un primer momento.

Respecto a la eliminación del fragmento mayor, en un principio debía ser la más sencilla, pero se complicó tras encontrar atrapado en su interior el paquete vasculonervioso medial del dedo, por lo que no hubo más remedio que retirarlo. Es importante remarcar aquí que, en casos como este, cuando vayamos a retirar un fragmento nervioso, debemos hacer una correcta neurotomía para evitar la aparición de un neuroma de muñón, con el consiguiente dolor postquirúrgico y las complicaciones futuras que ello conlleva.

Por otro lado, también debíamos preservar la piel y grasa plantar del primer dedo para prevenir posibles fibrosis y/o ulceraciones posteriores cuando el tejido tuviera que soportar la carga, punto este especialmente importante por el tamaño y localización de la lesión distal, la cual había provocado una importante retracción de la grasa plantar, la cual hubo que respetar en la medida de lo posible a la hora de extraer el tofo.

No podemos saber a ciencia cierta cómo evolucionará en un futuro, pero si tenemos en cuenta la edad de la paciente y su biomecánica, estamos seguros de que el tratamiento elegido es el idóneo para devolverle la calidad de vida perdida.

En conclusión, el presente caso clínico nos pone de manifiesto una realidad. El/La podólogo/a ha de ser capaz de diferenciar este tipo de lesiones, de planificar un proceso encaminado a la eliminación definitiva de las mismas y de proponer una alternativa de tratamiento a los pacientes que, por su particular situación, quedan fuera de los circuitos habituales de la Sanidad, trabajando con equipos quirúrgicos de varios profesionales y empleando las pruebas complementarias que crea convenientes. No obstante, ninguna prueba complementaria puede suplir un buen diagnóstico clínico. Desde un primer momento teníamos claro que estábamos ante un proceso de tofos gotosos, y a pesar de las pruebas radiológicas y de laboratorio que indicaban otras patologías, nuestra experiencia e intuición nos marcaron el camino correcto en todo momento.

\section{CONFLICTO DE INTERESES}

Los autores declaran que no presentan ningún conflicto de intereses relevante en este artículo.

\section{FINANCIACIÓN}

No existen fuentes de financiación públicas o privadas en la realización del presente artículo.

\section{BIBLIOGRAFÍA}

1. Shurnas PS, Coughlin MJ. Artritis del Pie. En: Coughlin - Mann - Saltzmann. Pie y Tobillo. Vol 1. 8. a edición. España: Marbán; 2011 p. 732-6.

2. Salgado A, Barquinero J. En: Interpretación Clínica de los Datos de Laboratorio. $3^{a}$ Ed. España: Química Farmacéutica Bayer SA; 1996. p. 12-3.

3. Juárez-Jiménez JM, Córdoba-Fernández A, Rayo-Rosado R. Hallux Rígidus, Multicausalidad, evolución y alternativas terapéuticas. En: Monografías XXXIII Congreso Nacional de Podología. Consejo General de Colegios de Podólogos. España: Jiménez Mena SL; 2002. p. 237-46.

4. Asunción-Márquez J, Martín-Oliva X. Hallux rigidus: etiología, diagnóstico, clasificación y tratamiento. Rev Esp Cir Ortop Traumatol. 2010;54(5):54-321. DOI: 10.1016/j.recot.2010.05.005.

5. Mercado OA. Artritis Reumatoidea. En: Federación Española de Podólogos. Atlas de Cirugía del Pie. Vol. 1. Cirugía del Antepie. España; 1995. p. 176-7.

6. Moreno-de la Fuente JL. Hallux Rígidus. En: Podología Quirúrgica. España: Elsevier; 2006. p. 169-77.

7. Boberg JS, Eilts CL. Interdigital Neuroma (Morton Neuroma) En: McGlamry's Comprehensive Textbook of Foot and Ankle Surgery $4^{\mathrm{a}}$ Edición. Holanda: Kluwer Health I Lippincott Williams \& Willkins; 2013 p. 117-23.

8. Co AY, Chang TJ, Camasta CA. Joint Salvage and Preservation Surgical Techniques for Hallux Limitus, en: McGlamry's Comprehensive Textbook of Foot and Ankle Surgery 4. ${ }^{a}$ Edición. Holanda: Kluwer Health I Lippincott Williams \& Willkins; 2013 p. 343-31. 